\title{
CHRONOLOGICAL ANALYSIS ON CONSCIOUSNESS OF EXPERTS TO SOCIETY
}

\author{
Kumi OKUWADA ${ }^{1}$, Yoshiko YOKOO ${ }^{2}$, and Naoto TSUTSUI ${ }^{3}$ \\ ${ }^{1} \mathrm{Ph} . \mathrm{D}$. (Engineering), Senior Fellow, \\ National Institute of Science and Technology Policy (E-mail: okuwada@nistep.go.jp) \\ ${ }^{2}$ M.A. (Domestic Science), Senior Research Fellow, Science and Technology Foresight Center, \\ National Institute of Science and Technology Policy (E-mail: yokoo@nistep.go.jp) \\ ${ }^{3} \mathrm{Ph} . \mathrm{D}$. (Science), Manager of Information Engineering Department, \\ i's FACTORY co., ltd. (E-mail: tsutsui@isfactory.co.jp)
}

\begin{abstract}
Visualizing through a text-mining approach for continuous foresight survey reports revealed chronological trends of experts' consciousness over 40 years. The direction of their consciousness largely changed after 2000 onward having stronger relationships with society, following subdivided and relatively incremental decades before 2000 . Their consciousness to society has spread widely after 2000 . The chronological changes of some frequently occurring words revealed some emerging fields and their necessity of societal embeddedness. However, there has still been a large inclination among the fields, which suggests an insufficiency of their consciousness to society. This has led us to have fears of essential seeds-needs incongruency in innovation ecosystems in Japan.
\end{abstract}

Keywords: Societal embedding, Consciousness, Foresight, Text-mining, High-frequency appearance

\section{Introduction}

It is well-known that "Science in society and science for society" was declared to supplement objects of science and the use of scientific knowledge in the World Conference on Science in $1999^{1}$. After the declaration, the process of societal embedding has gradually come to be regarded as an important part of R\&D activities in Japan. However, many efforts to implement $R \& D$ results must have occurred even before this declaration, because expectations for contributions to future society had always acted as a main rationale behind the idea that the R\&D activities should be supported by public investment.

On the other hand, it is not clear that scientists and engineers have sufficient consciousness to relate to society in their R\&D activities. Further, we could not recognize the transformation of their consciousness after the declaration. Due to a lack of clues, we have not been able to discuss in what specific fields their consciousness should be emphasized more and pushed toward their societal implementations.

The foresight surveys are regarded as an accumulation of expectations for the future by experts in varied fields. The texts of their past reports are regarded as very rare material to comprehend the consciousness of experts and their transformation. Japanese foresight activities especially have continued adding some improvements over the 40 years ${ }^{22,3)}$. With their open data of past reports, we may observe chronological changes of experts' consciousness to society.

There have existed huge amounts of description which analyzed on past events and current situations. However, documents which consist only of expectation forward the future are few. Among them, open data sets which can be available for chronological analysis are much less. The survey reports of Japanese foresight activities are very valuable samples which meet these conditions. The participants of the foresight surveys were experts who were researchers, engineers and stakeholders in academia and industry in wide fields of science and technology. They were the optimal groups in those days in Japan who could describe the expectation for the future. After the long continuity of the surveys, we have got an adequate quantity of the accumulation of the description for chronological analysis.

This research is a trial to visualize general trends and emerging fields in experts' consciousness in relation to society for the past 40 years through observing appearing frequencies of words by text-mining. Text-mining has already been well-recognized mainly in marketing after popularization of internet technology. Advanced search technologies have made keyword analyses and bibliometrics much easier. As we are now in big data era, text-mining is again focused on as a method which can show underlying trend and qualitative transformation among large amount of archives ${ }^{4}$. The big archives give us the possibility of many kinds of chronological analyses in long terms. For example, visualization of human 
mobility by text-mining in recorded history in English over 2000 years gave us overwhelming sensation in our historical understanding ${ }^{5}$. Text-mining has also been paid attention as new foresight tools ${ }^{6), 7)}$. Some qualitative transformation in chronological changes in science and technology trends could be revealed with original data sets and contrivance of text-mining ${ }^{8)}$. Here, we may show the usability of text-mining in a trial of finding chronological changes in experts' consciousness. Through this method, we may renew our understanding over the past 40 years.

We also discuss the sufficiency of their consciousness toward societal embedding by adopting "service" as a representative word. Importance and progress of service are no longer to be necessary to explain in business. On the other hand, academia of service science has also been established in many countries after the National Innovation Summit in Washington, D.C. in 2004 "). We consider that "service" is a good example word in order to validate the infiltration into recent experts' consciousness.

\section{Subjects and procedures of analysis}

\subsection{Subjects in analysis}

We recognized that experts' expectations of the future could be found in the results of foresight activities, as scientists could be free of their own accumulated academic works and engineers could be free of existing businesses only when they think about the distant future. Globally, foresight studies have been more popular, because some specific types of evidences are required in order to make organizational strategies at both the company and national level. However, it is not easy to find some chronological changes in the foresight results as most foresight activities have been not continuously carried on.

The Delphi technique, which was developed by the RAND Corporation in the 1950s, is one of the foresight methodologies. It has often been used to attempt to reach a consensus among participants or stakeholders. The same questions are delivered repeatedly to the same group of experts. In subsequent rounds, the former results are fed back to the respondents and they can see how far their opinions are from the majority. Some respondents change their former answer. The repetition of this process leads to a convergent opinion. The Delphi technique has been regarded as a useful tool for seeking long-term perspectives that depend only on instinctive insights. In Japan, the Science and Technology Agency started the survey mainly in the scientific and technological fields in the 1970s.

The Delphi survey in Japan is unique in terms of its scale, continuity, and inclusiveness ${ }^{2)}$. It covers a variety of scientific and technological fields, and a large number of experts are involved in surveys as committee members and respondents. Each survey has looked ahead 30 years from the time of the survey. Recent foresight activities in Japan have become more comprehensive by combining the Delphi technique with other methods. The recent foresight summarized forward-leaning comprehensive mega-trends from the integration of some methods $^{3)}$. The Delphi surveys in Japan have been unique and valuable as they have been continued every 5 years for the past 40 years, although their participants were limited to Japanese experts. All results have been opened as survey reports.

As a merit to the continuity of the surveys, they have proven able to evaluate the past foresight activities ${ }^{10)}$. The post-project assessments, mainly from the viewpoint of realization, were started after 20 years of early surveys. The results in the assessments have also been opened together within the recent reports. They could distinguish both the realized and unrealized technologies. The reports lead statistical probabilities and tendencies by fields, and reveal barriers against realizations and hastiness in some technologies ${ }^{2}$.

The main analysis subject in this research is referred to as "topics" as written in the questionnaires in all of the Delphi surveys. The possibility of realization in the future was asked on each topic in the questionnaires. The questions on each topic were repeated to obtain converging answers among many experts, because the convergence by repetition is the essence of the Delphi method. Each topic was about 40 to 50 characters long in Japanese. Many aspects in science and technology have been presented in the topics. They included discoveries and inventions in basic science and technology with their hidden potential, implementation and diffusion in society, and related institutions and produced influences in society. The topics like Table 1 were set by panels of subcommittee members. The panels were established according to the scientific and technological fields and social goals. Each panel consisted of 10 - 15 members, covered by academics, industry people and other stakeholders. The topics were set from their fresh perspectives while referring back to those in the previous Delphi surveys. They examined the topics of the previous surveys, renewed them and added more remarkable ones. Therefore, the questionnaire in each survey consisted of a mix of continued and new topics.

For example, twelve panels were established in the latest 2010 survey $^{2}$. The panel members set topics and also described their views after looking at the questionnaire results in the report. The respondents to the repeated Delphi questionnaires consisted of about 3000 people in the survey, who also 
consisted of academics, industry people and other stakeholders. They also contributed their views to the topics as well as answered the questionnaires. Thus, the report could be regarded as the descriptions of expectations for the future by 3000 people from various background, concerned with science, technology and innovation in Japan.

The total number of topics was 8147 in 9 surveys during the 40 years. After excluding the words that were extremely general, the words suitable for this research were approximately 6700 nouns. The original data is in Japanese. Many nouns easily transform into other forms in Japanese. Many verbs and adjectives are made by coupling nouns and suffixes. Furthermore, many compound words are made by the simple combination of plural nouns. On the other hand, a noun often has some different meanings. Some nouns should be translated into more precise English words in the topics, depending on the concepts that the topics represent. Therefore, it is not important whether the extracted words are nouns or other forms in the English translation, so we describe them as simply "words" in the discussion of this research.

\subsection{Procedure in analysis}

\section{(1) Procedure for general trends}

The experts' consciousness was analyzed by text-mining in this research. We observed transitions in the frequency of appearances of nouns used in topics in the surveys. We basically assume that the high-frequency appearance of nouns indicates experts' interests and attentions, and discuss further what the observed transitions mean.

Their transitions were observed in the following three approaches.

a) Extraction of frequently appearing nouns and measuring their chronological changes from all topics in 40 years

We firstly extracted frequently appearing nouns. The number of topics containing each noun was counted by each survey. The top 100 nouns in all topics for 40 years were specified in terms of total frequency of appearance. Their chronological changes were observed in ratios of the topics including the top nouns.

Table 1 Examples of the topics including "service" in the $9^{\text {th }}$ Delphi survey report opened in $2010^{2)}$

(Extracts from the English version of the survey report)

\begin{tabular}{|c|c|}
\hline Topic numbering and classified area & Examples of topics including "service" \\
\hline $\begin{array}{l}1-2 \\
\text { Advanced computing systems }\end{array}$ & $\begin{array}{l}\text { Network systems responding dynamically to the operating status and } \\
\text { environmental condition of the inside and/or outside of the systems to provide } \\
\text { required services with high reliability and without human intervention or any } \\
\text { interruption. }\end{array}$ \\
\hline $\begin{array}{l}\text { 2-2 } \\
\text { Cloud computing }\end{array}$ & $\begin{array}{l}\text { In the system providing various services to various users by flexible connection } \\
\text { of more than a hundred million computers, an advanced autonomous service } \\
\text { creates new value-added information or new functional services from existing } \\
\text { functions and services or from the group of data lying in such services. }\end{array}$ \\
\hline $\begin{array}{l}2-36 \\
\text { Socialization of } \\
\text { information }\end{array}$ & $\begin{array}{l}\text { Establishment of a system that finds out whether the proposed service } \\
\text { conforms to the laws and regulations of each country by retrieving them, and } \\
\text { indicates the conditions for providing such service in each country. }\end{array}$ \\
\hline $\begin{array}{l}\text { 2-69 } \\
\text { Contents service }\end{array}$ & $\begin{array}{l}\text { Simulations of the changes in the customer's purchase activity and sense of } \\
\text { value from various standpoints before a service starts to be provided by a } \\
\text { company. }\end{array}$ \\
\hline $\begin{array}{l}\text { 10-56 } \\
\text { Globalization, value-adding and } \\
\text { market creation }\end{array}$ & $\begin{array}{l}\text { Recognition technology to analyze the services that the person requires and to } \\
\text { provide appropriate advice and guidance to the service provider. }\end{array}$ \\
\hline $\begin{array}{l}\text { 12-20 } \\
\text { Life support strategy }\end{array}$ & $\begin{array}{l}\text { Diffusion of logistics services that deliver medicine and food for medical } \\
\text { treatment, without requiring a hospital visit, to support the lives of elderly } \\
\text { persons and patients of lifestyle diseases living in inconveniently located areas, } \\
\text { such as mountainous regions, by establishing a remote consultation system and } \\
\text { health care system using IT technologies. }\end{array}$ \\
\hline
\end{tabular}


b) Mapping for frequently-appearing nouns and their chronological changes during 40 years

In order to grasp an overall picture of their chronological changes, a two-dimensional distribution map was created by correspondence analysis among the top nouns. There, we could also observe co-occurrence as the relationship among the 100 top nouns of a) and the center positions of each survey year. This led the discussion on top nouns that characterized each survey and on their distances between surveys with some directions.

c) Comparison in amounts and contents of characteristic nouns in each survey

The top 100 nouns appearing most frequently in each survey were firstly extracted. Next, the nouns whose frequency of appearance in a specific survey accounted for over 20 percent of their total appearances in all surveys were specified to extract the characteristic nouns in each survey. Necessarily, some characteristic nouns in c) are not included in the top 100 words extracted in a).

In order to extract characteristic nouns in each survey, weighting by the amount of topics was needed in order to eliminate the effects of survey size, because the number of the topics was largely varied in the range of 644 to 1072 in 9 surveys.

\section{(2) Procedure for "service" trend}

The comparative discussions on "service" was added in this research, because it is a representative word that would only appear when concerns with society were voiced. Service science and service innovation are relatively new concepts. Some examples including the noun "service" in the recent survey report in $2010^{2)}$ are shown in Table 1. The reason why authors thought "service" was a suitable sample for detailed investigation is described in 4-1 using results in Table 3.

The expectations of "service" were observed in the following three approaches in this research.

a) Measurement for chronological change in appearance of "service"

The numbers of topics including "service" were counted for each survey. The ratio of the topics including "service" to the total topic number in each survey was observed.

b) Observation for co-occurrence of "service" and the related words

The relations with the adjacent and other words were observed in the topics including "service" in each survey by co-occurrence network analysis.

c) Observation on "service" in a recent report
In order to consider about recent situation, a detail analysis both their topics including "service" and descriptions on service in the recent report was added.

\section{Findings in general trend analysis}

\subsection{Frequently appearing words and their relationship during 40 years}

The top 100 words extracted in terms of frequency of appearance are shown in Table 2, which experts have been paid attentions to for the past 40 years. The high frequencies of appearance of the words of "investigation", "development", "practical-use", and "widespread" are not significant as exceptions. They had been recommended to use in topics through the early surveys as jargon to specify the R\&D stage of the topics.

Figure 1 shows maps of correspondence analysis performed in order to understand relationships between the top words and the survey years. The larger distribution map consists of co-occurrence in appearances among the top words. The top words that have a close relationship in the topics are located closely together. The axes and the frame were placed on it in order to help understand the relationship, but they do not have any meanings. The red points show the centers of the survey years. The smaller map consisted of the pulled-out red points in order to easily understand their general trend over 40 years.

More common top words in survey years are located near the center of the distribution map. The positions of survey years in 1982, 1987 and 1992 are also near the center as less characteristic years. We should rather pay attention to the characteristic survey years and their vicinity of top words. The position of 1971 is lower and far from the center of this map. The top words such as "computer", "automation", and "processing" can be seen in the vicinity of 1971 and 1977. They indicate that automation through utilization of computers was a focus of attention during the 1970s.

The most drastic chronological change of the survey years can be seen in the position of 2005 and 2010. They are in the left side and out of an alignment shaped before 2000 in the map. This indicates that another type of trend happened and accelerated in a completely different direction in 2000s.

The top words in the vicinity in 2005 and 2010 such as "corporation", "society", "economy", and "community" indicate social perspectives. They also related to the words showing the fields of "environment", "energy", and "information". This remarkable change will be discussed more deeply with another result in the following section of 3.3. 
Table 2 Top 100 words in frequency of appearance in all topics

technology, development, practical-use, system, widespread, use, possible, investigation, environment, function, information, establishment, material, artificial, realize, degree, control, production, energy, automation, device, substance, structure, management, cure, telecommunication, resource, satellite, safety, utilize, manufacture, organism, mechanism, city, computer, course, japan, efficiency, treatment, human, cell, water, forecast, home, robot, inside, space, method, present, size, region, earth, occurrence, power-generation, gene, chemical, observation, automobile, general, molecular, design, dispose, network, society, evaluation, amount, light., interval, number, machine, level, improvement, biological, pollution, ocean, company, inside, precision, gas, various, high-level, element, body, battery, fuel, spatial, prevention, less, economy, natural, synthesize, influence, equipment, electron, heat, diagnose, style, barrier, individual, available

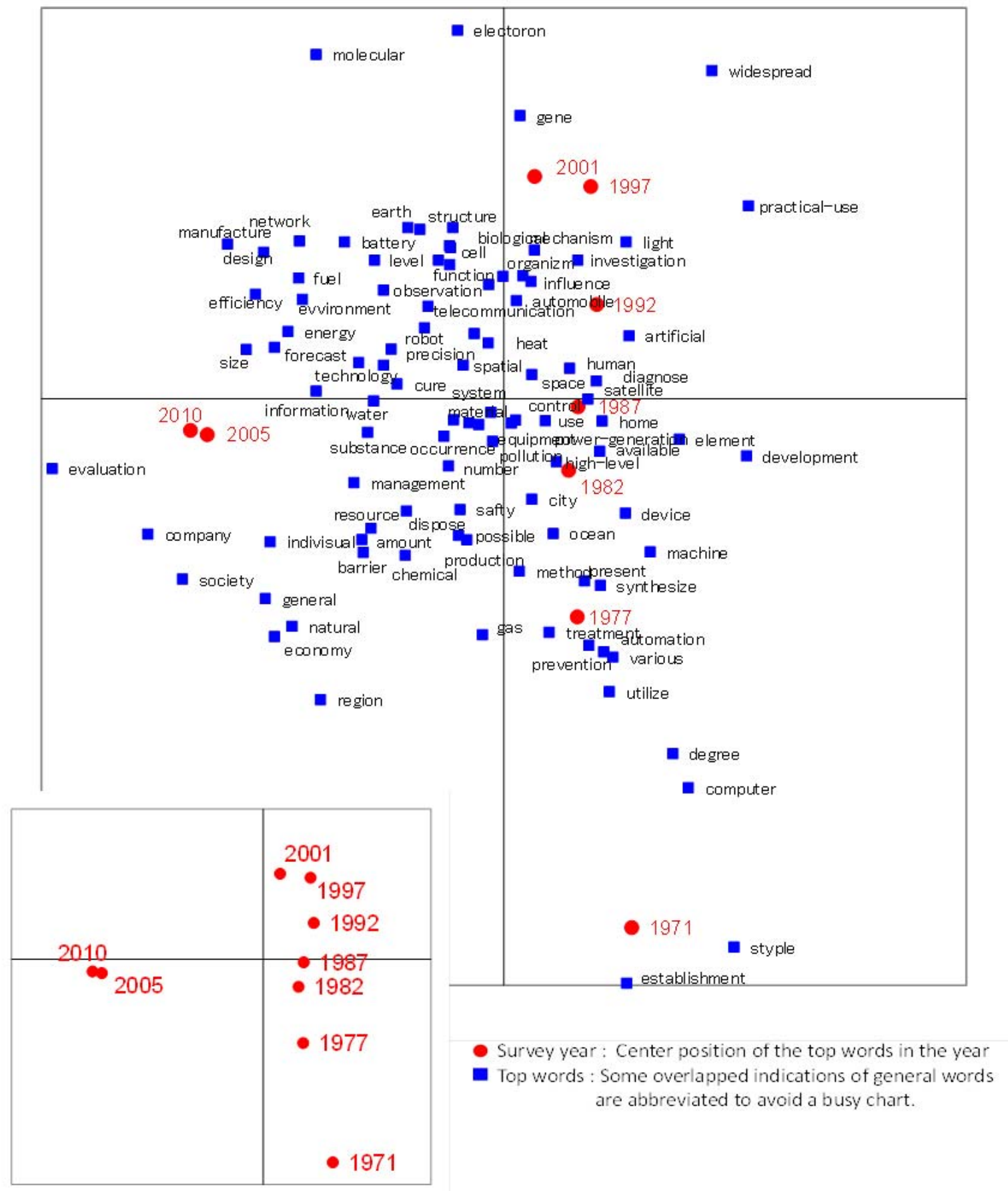

Fig.1 Correspondence for the top words and survey years 

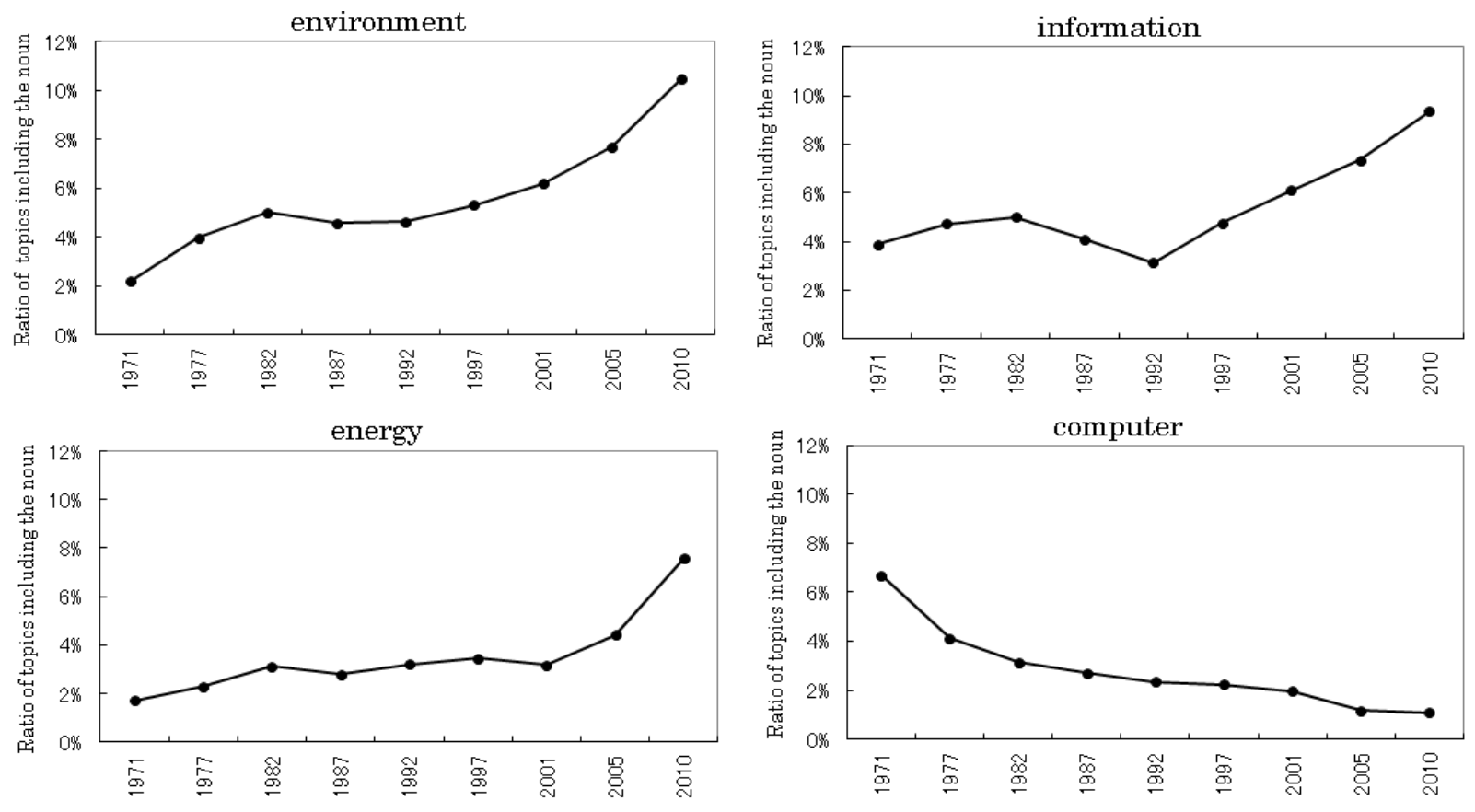

Fig.2 The top words showing characteristic chronological changes

\subsection{The top words showing characteristic chronological} changes

The most remarkable chronological changes in the appearance frequency of the top words are shown in Figure 2. The ratios of topics containing "energy", "environment", and "information" have increased since the 1990s and 2000s, respectively, which have reached to $8-10 \%$. This suggests a surge in the consciousness of experts to global problems in society.

The contrastive changes in "Information" and "computer" are very interesting. The gradual downward trend in "computer" suggests that experts have unconsciously become to use computer machines and related technologies in various aspects of society. In other words, the decreasing trend is a result of the societal embedding of computer technologies. The main interest of experts seems to have shifted into "information", the contents brought about by computer technologies after the spread in internet technologies in the last half of the 1990s.

\subsection{Change in characteristic words in each survey}

The words that are more frequently used in only one survey are considered as characteristic focuses of attention for the survey year. In the frequently appearing words ranked within 100 th in a survey, the words whose appearances in the survey occupy more than $20 \%$ of its total appearances in all surveys were extracted as characteristic words for the survey. In order to eliminate the effects of survey size, the data on frequency of appearance was weighted by number of topics of each survey.
The difference between before and after the weighting by the number of topics is shown with characteristic words in Table 3. We firstly found in Table 3 that the number of the characteristic words before weighting has been out of proportion to the number of topics in the surveys. Furthermore, it is remarkable that the characteristic words after weighting were less in amount during from the 1980 s to the early 2000 s, when the survey sizes were large. However, it was not the decades when the variety spread, though the survey sizes were large in amount. Resemble finding had already shown that the common top words gathers around the center of the distribution map in Figure 1 . We could recognize the decades as a subdivided and relatively incremental period in Japan. The experts of those days may have been less sensitive to social changes.

We should pay more attention to the characteristic words after weighting in the 2000s. They are greater in amount and qualitatively different from the characteristic words before 2000.The topics in the 2010 survey have the largest number of characteristic words. The report ${ }^{3}$ stated that this survey design was intended to break the walls between fields and redundancy of perspective among the subcommittees was permitted in order to prioritize finding the attentions among experts rather than covering large fields. However, more new characteristic words appeared. There are many words that show relationships with society and its changes, for example, "society", "region", "life", "economy", "organization", and "aging". Such words as "efficiency", "evaluation", and "institution" present the concern for a lack in previous perspectives. Most symbolic is "society" was a one of the characteristic word $\mathrm{s}$ in 2010. 
Table 3 Characteristic words in each survey

\begin{tabular}{|c|c|c|c|c|}
\hline $\begin{array}{l}\text { Survey } \\
\text { year }\end{array}$ & $\begin{array}{l}\text { Size } \\
\text { (Number } \\
\text { of Topics) }\end{array}$ & $\begin{array}{l}\text { Number } \\
\text { before } \\
\text { weighting }\end{array}$ & $\begin{array}{l}\text { Number } \\
\text { after } \\
\text { weighting }\end{array}$ & Characteristic words after weighting by the number of topics in the survey year \\
\hline 1971 & 644 & - & 22 & $\begin{array}{l}\text { establishment, degree, computer, utilize, perfect, style, education, factory, overlap, } \\
\text { progress, unmanned, medicine, television, main, telephone, nuclear-power, cultivation, } \\
\text { fiber, plant, search, appearance, massive-scale }\end{array}$ \\
\hline 1977 & 656 & 6 & 15 & $\begin{array}{l}\text { establishment, style, pollution, methodology, prevention, metropolis, work, } \\
\text { countrywide, condition, facility, swift, exchange, main, training, network }\end{array}$ \\
\hline 1982 & 800 & 4 & 4 & house, unmanned, coal, maintenance \\
\hline 1987 & 1071 & 20 & 4 & application., science, intelligence, physiology \\
\hline 1992 & 1149 & 22 & 4 & application, intelligence, build, carbon-dioxide \\
\hline 1997 & 1072 & 22 & 1 & japan \\
\hline 2001 & 1065 & 26 & 6 & widespread, japan, company, electron, process, support \\
\hline 2005 & 858 & 23 & 14 & $\begin{array}{l}\text { general, evaluation, company, nano, activity, actively-use, correspondence, our-country, } \\
\text { form, service, risk, support, analysis, regenerate }\end{array}$ \\
\hline 2010 & 832 & 39 & 39 & $\begin{array}{l}\text { environment, energy, resource, efficiency, manufacture, evaluation, region, size, society, } \\
\text { actively-use, economy, design, natural, nano, support, life, risk, fuel, activity, battery, } \\
\text { service, circulation, product, institution, simulation, our-country, organization, } \\
\text { correspondence, CO2, bio, construct, aged, disease, infrastructure, cost, efficiency, } \\
\text { disaster, electric-power }\end{array}$ \\
\hline
\end{tabular}

\section{Findings in analysis on "service"}

\subsection{Chronological changes in topics including "service"}

"Service" is regarded as one of the words that are used by experts only when they strongly have a consciousness toward society. Many technologies would be embedded into society as some kinds of services. Although "service" was not included in top 100 words over the past 40 years, as shown in Table 1, it is one of the characteristic words in the 2010 survey, shown in Table 3. As described in the introduction of this paper, importance of service concept in business was fully recognized and service science has established its research field in academia in those days. We can assume that these should be the reason why "service" appeared as the characteristic word in this timing. We considered that this word was suitable for more detailed investigation as recent trend in Japan.

Figure 3 shows a chronological change in the number and ratio of topics including the word of "service". The ratio of the topics including "service" to the total number in each survey has slightly increased after 2000, which" reached 2.9\% in 2010. The attention or expectation to "service" corresponds to around $1 / 3$ the amount of "environment", "information", and "energy", shown in Figure 2.
Co-occurrence relations with the adjacent words on "service" were shown in Figure 4 in a style of network analysis. The arrows show the sequence tendencies in their appearances. The topics including "service" before 2000 were too few to construct clusters with the adjacent words. The adjacent words and the clusters indicate the contents of expectations for service. The adjacent words in the 2001 survey mainly show the application fields of service. The most adjacent words in the 2005 survey show social values that service could bring about.

The adjacent words in the 2010 survey are implicated in more diversified concepts. Technical words and application fields already disappeared in the adjacent words. On the other hand, more abstract and more general words increased. This allows us to consider possibilities of diversification in service science and service innovation.

\subsection{Inclination in fields on consciousness to "service"}

In order to discuss the current situation regarding "service", a more detailed analysis is shown here on both topics including "service" and descriptions on "service" in the recent report". The report opened in 2010 stated that the recent survey was carried out under a fully worked-out plan to synchronize with transformation in science and technology policies in Japan ${ }^{11)}$. 


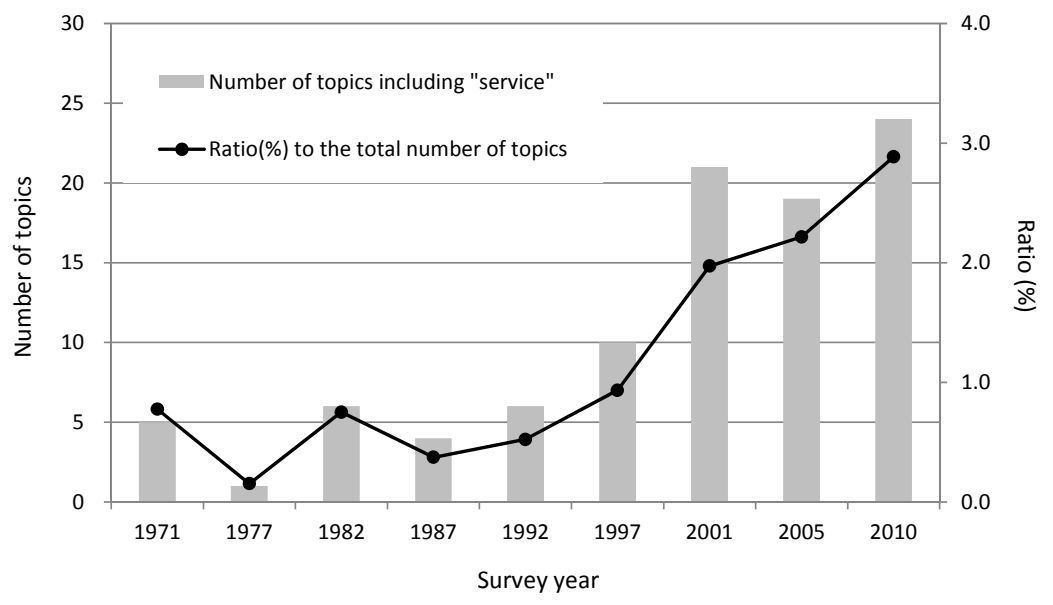

Fig.3 Number and ratio of topics including "service"

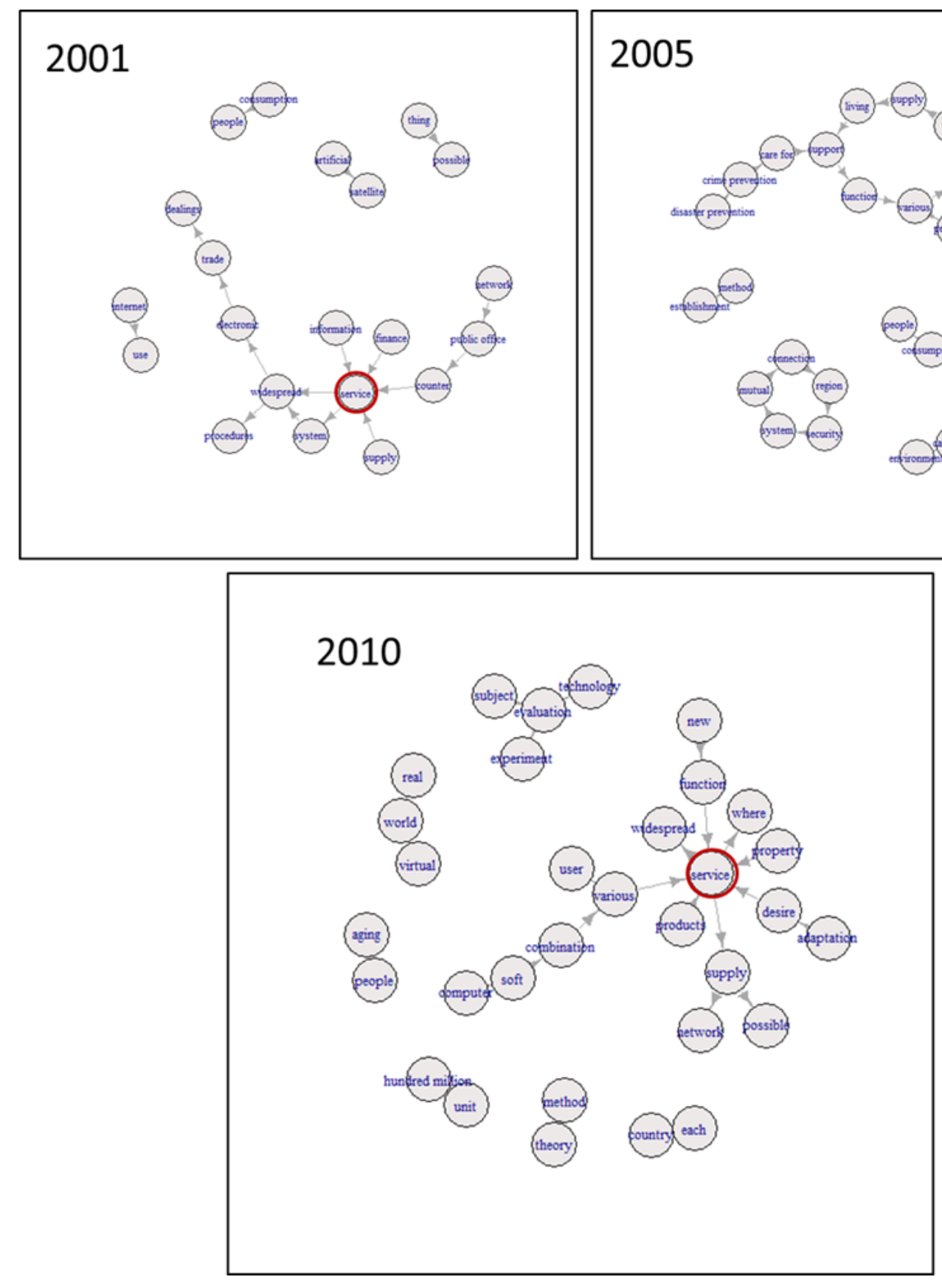

Fig.4 Chronological changes after 2000 in the networks surrounding "service" 
The panels were called only as numbers, not as existing field names, to avoid preconceptions. The panels set their discussion fields on their own as shown in Table 4. The duplication among panels in their discussion of a selection of topics was tolerated because the extraction of more remarkable keywords for innovation was given priority over covering all fields and areas. In other words, it was done with some trials in order to take away existing concepts of fields as well as to break up some borders on disciplines and sectors.

Having pre-known these conditions in the survey, the results in Figure 5 surprised us. They showed a marked inclination of topics including "service". The classified areas including "service" in their area names were only two. Furthermore, the members in three panels and their respondents over 3000 experts did not describe "service" at all in all texts in the relevant sections of the report.

Figure 4 shows that the expectation to "service" is extremely deficient except in the information, management, and related fields. This reminds us that service science in Japan started from a comprehension of foreign documents that were described on bounded scopes with information, economy, and management studies, and with financial business ${ }^{12)}$.

It also suggests that service science has not subsequently developed forward into wider fields and areas in Japan.
Table 4 Panel structure in the $9^{\text {th }}$ survey $^{2)}$

\begin{tabular}{|c|c|}
\hline Panel & Viewpoint (defined by each panel) \\
\hline No. 1 & $\begin{array}{l}\text { Utilization of electronics, communication, and nanotechnology in a } \\
\text { ubiquitous society }\end{array}$ \\
\hline No. 2 & Information technology including media and contents \\
\hline No. 3 & Biotechnology and nanotechnology to contribute to humankind \\
\hline No. 4 & $\begin{array}{l}\text { Medical technology to contribute to healthy lifestyles of the nation's people } \\
\text { using IT, etc. }\end{array}$ \\
\hline No. 5 & $\begin{array}{l}\text { Understanding of dynamics of space, earth, and life, and science and } \\
\text { technology which expand the region of human activity }\end{array}$ \\
\hline No. 6 & Promotion of diverse energy technology innovations \\
\hline No. 7 & Necessary resources, including water, food, minerals \\
\hline No. 8 & Technologies for protecting environment and forming sustainable society \\
\hline No. 9 & $\begin{array}{l}\text { Fundamental technologies, including substances, materials, nanosystems, } \\
\text { processing, measurement, etc. }\end{array}$ \\
\hline No. 10 & $\begin{array}{l}\text { Manufacturing technologies which totally support development of industry, } \\
\text { society, and science and technology }\end{array}$ \\
\hline No. 11 & $\begin{array}{l}\text { Strengthening of management led/required by advancement of science } \\
\text { and technology }\end{array}$ \\
\hline No. 12 & Infrastructure technologies supporting daily life base and industrial base \\
\hline
\end{tabular}

Needless to say, service concepts have already been paid attention to many businesses and public works. For examples, medical services and environmental services have produced big business opportunities and created significant employment opportunities. There are many kinds of private services and administrative services in our society, which suggests that there is still a considerable estrangement between the development of service in society and the research for service innovation in academia. Some kinds of political measures have recently been attempted to increase interdisciplinary approaches toward service innovation. However, they have not been able to bring about sufficient effects to upsurge the consciousness of experts in most fields.

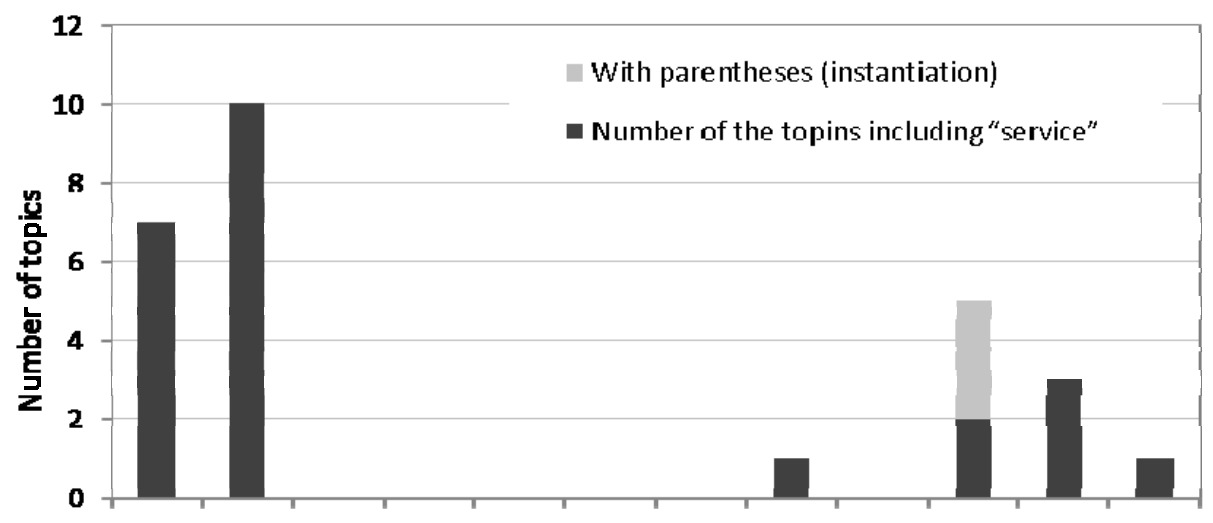

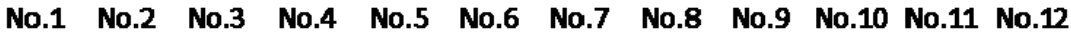

\begin{tabular}{|c|c|c|c|c|c|c|c|c|c|c|c|c|}
\hline $\begin{array}{l}\text { Esbablshment of } \\
\text { classinled areas } \\
\text { Including"service" }\end{array}$ & - & 0 & - & - & - & - & - & - & - & - & 0 & - \\
\hline $\begin{array}{l}\text { Incluskon of "service" } \\
\text { In the descripton of } \\
\text { the report }\end{array}$ & 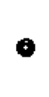 & 0 & - & $\boldsymbol{\Delta}$ & 0 & - & $\boldsymbol{\Delta}$ & 0 & $\boldsymbol{\Delta}$ & 0 & 0 & 0 \\
\hline
\end{tabular}

No. : Panel No. (fields in discussion shown in Table 4)

Class areas : $\circlearrowleft$ included - not included

Description: (O) many $\bigcirc$ some $\triangle$ few - not included

Fig.5 Inclination in expectation to "service" in the topics and description in the $9^{\text {th }}$ survey report 
As "service" is just an example word in this analysis, it may be insufficient for a discussion of national R\&D system. However, the severe inclination among fields, as shown in Figure 5, lets us recognize some fears of essential seeds-needs incongruency in the innovation ecosystem in Japan.

\section{Conclusion}

The text-mining approach for the opened reports of the continuous foresight surveys in Japan revealed chronological changes of experts' consciousness during a 40-year time span. The direction of their consciousness largely changed after 2000 onward having a stronger relationship with society, after a subdivided and relatively incremental period before 2000 . Their consciousness to society has been found to spread their wideness of ideas.

The decreased trend of "computer" was observed as a result of societal embedding of computer technologies. Recent upsurges in attentions for "information", "energy", and "environment", and the strength in their relationships with societal issues, suggest that they are emerging fields where more innovative concepts are needed. It is a most symbolic finding that "society" was one of the characteristic words in the topics in 2010 after 40 years of continuous surveying.

On the other hand, a more detailed observation on "service" as a representative word toward embedding to society suggests that there has still been a large inclination among the fields, which further indicates an insufficiency in experts' consciousness to societal implications. This led us to have some concerns regarding essential seeds-needs incongruency in innovation eco-system in Japan.

We can state that the perspective on the direction of scientific and technological development has been causing the biggest qualitative change in the past 40 years. It has accorded with the necessity for an introduction of concepts of back-casting from problem-solving goals on societal issues in policy-making processes on science, technology and innovation. We can also state that the political transformation from the 3rd Science and Technology Basic Plan to the 4th one in 2011 ${ }^{11)}$ in Japan, which was forward more issue-oriented, was inevitable and reasonable. We imagine that any resemblance of a general trend is likely to have been present in other advanced countries. However, it is impossible to enact more global discussions, because comparable data in continuity has not existed in other countries. We expect that other kinds of approach using big data may reveal global trends in the near future.

In this research, we could reveal quantitative chronological changes of experts' consciousness using simple text-mining of extracting single words. On the other hand, in order to discuss on qualitative changes, more complex semantic analyses must be necessary For example, more detailed analyses of complex words and compound words like Figure 4 may be useful. Furthermore, relations between subjects and predicates and judgment of affirmation and negation must also be noteworthy as research subjects to find such quality changes.

In addition to them, this research was done under an assumption that the description in the foresight reports on science and technology has included experts' consciousness onward future society according to the survey design. However, the verification of this assumption is not possible in the present methodologies. We also hope developments of some new semantic tools which make such verifications possible.

\section{References}

1) UNESCO (1999), Declaration on Science and the Use of Scientific Knowledge, (World Conference on Science(1999) Science for the Twenty-first Century - A New Commitment, World Conference on Science, Budapest Hungary ).

2) NISTEP (2010), The 9th Science and Technology Foresight: The 9th Delphi Survey, NISTEP Report No. 140 (in Japanese).

3) NISTEP (2010), Contribution of Science and Technology to Future Society - Summary on the 9th Science and Technology Foresight -, NISTEP Report, No. 145 (in Japanese).

4) Schich,M., Song,C., Ahn,Y., Mirsky,A., Martino,M., Barabási,A., and Helbing,D. (2014), A network framework of cultural history, Science, 345(6196), pp.558-562.

5) Reardon, S. (2014), Text-mining offers clues to success, Nature, 509, p.410.

6) Yokoo,Y., and Okuwada,K. (2013), Identifying expected areas of future innovation by combining foresight outputs, Foresight, 15(1), pp.6-18.

7) e.g. IARPA (2011), Foresight and Understanding from Scientific Exposition(FUSE), IARPA-BAA-10-06.

8) e.g. Arino,K., Furukawa,T., Shirakawa,N., and Okuwada,K. (2012), Temporal network analysis of emerging technologies: Topic transition in World Wide Web (WWW) conferences, Proc. of International Conference on Industrial Engineering and Engineering Management, pp.1108-1112.

9) Council on Competitiveness (2004), Innovate America: Thriving in a World of Challenge and Change (National Innovation Initiative Summit and Report).

10) Yokoo,Y., and Okuwada,K. (2012), Validity of foresight derived from the evaluation of past activities in Japan, International 
Journal of Foresight and Innovation Policy, 8(4), pp. 296-310.

11) e.g. Government of Japan (2011), The 4th Science and Technology Basic Plan (FY2011-FY2015).

12) e.g. Ifm and IBM (2008), Succeeding through service innovation: A service perspective for education, research, business and government. Cambridge, United Kingdom: University of Cambridge Institute for Manufacturing.

13) NISTEP (2012), Tracing the direction of research and development shown in past Delphi surveys, DISCUSSION PAPER, No. 86 (in Japanese).

14) Okuwada,K., Yokoo,Y., Tsutsui,N., and Iwasaki,T. (2013), Chronological changes in consciousness on science and technology observed in the Delphi surveys during 40 years, 2013 IEEE ITMC \& 19th ICE Conference (Hague).

\section{Acknowledgement}

Authors appreciate all the participants in the past foresight surveys for their efforts of having left the valuable data which enabled this analysis. It is an extremely rare intellectual asset with long-term continuity under open data policy.

i) Some figures and tables in this paper were already reported by the authors in a discussion paper (2012) ${ }^{13)}$ in Japanese.

ii) Some parts of discussion in this paper overlap with an oral presentation of the authors in 2013 IEEE ITMC \& 19th ICE Conference (2013) ${ }^{14)}$. 